\title{
Sleep apnea and risk of pneumonia: a nationwide population-based study
}

\author{
Vincent Yi-Fong Su MD, Chia-Jen Liu MD, Hsin-Kai Wang MD, Li-An Wu MD, Shi-Chuan Chang PhD, \\ Diahn-Warng Perng PhD, Wei-Juin Su MSc, Yuh-Min Chen PhD, Elizabeth Ya-Hsuan Lin BSc, Tzeng-Ji Chen PhD, \\ Kun-Ta Chou MD
}

\begin{abstract}
Background: Evidence evaluating the risk of pneumonia in patients with obstructive sleep apnea is limited and mostly focuses on patients who receive continuous positive airway pressure (CPAP) therapy or on pediatric patients. We aimed to explore the risk of incident pneumonia among adults with sleep apnea, either with or without the need of CPAP therapy.

Methods: From Jan. 1, 2000, we identified adult patients with sleep apnea from the Taiwan National Health Insurance Research Database. A control cohort without sleep apnea, matched for age, sex and comorbidities, was selected for comparison. The 2 cohorts were followed until Dec. 31, 2010, and observed for occurrence of pneumonia.
\end{abstract}

$\mathrm{O}$ bstructive sleep apnea is a prevalent disorder that affects about $20 \%$ of Americans and probably a higher percentage of Asian people. ${ }^{1,2}$ This disease is characterized by intermittent collapse of the upper airway during sleep that leads to intermittent hypoxemia and sleep fragmentation. ${ }^{3}$ Its close linkage to a variety of cardiovascular diseases and neurocognitive dysfunction has been demonstrated in the recent decade. ${ }^{4,5}$

Patients with obstructive sleep apnea were reported to have a higher risk of pulmonary aspiration of pharyngeal contents during sleep. ${ }^{6}$ Moreover, immune perturbations secondary to disrupted sleep may render them susceptible to invasion of pathogens. ${ }^{7}$ Both could potentiate the emergence of pneumonia. However, there are few studies addressing the relation between sleep apnea and pneumonia, and most of the studies involve small samples, are cross-sectional in design or lack information associated with development of pneumonia. ${ }^{8-11}$ We conducted this nationwide populationbased study to determine whether sleep apnea predisposed the development of pneumonia.
Results: Of the 34100 patients (6816 study patients and 27284 matched controls), 2757 $(8.09 \%)$ had pneumonia during a mean followup period of 4.50 years, including 638 (9.36\%) study patients and $2119(7.77 \%)$ controls. Kaplan-Meier analysis showed a higher incidence of pneumonia among patients with sleep apnea (log rank test, $p<0.001$ ). After multivariate adjustment, patients with sleep apnea experienced a 1.20 -fold (95\% confidence interval 1.10-1.31) increase in incident pneumonia. The risk was even higher among patients who received CPAP therapy.

Interpretation: Sleep apnea appeared to confer a higher risk for future pneumonia, possibly in a severity-dependent manner.
Competing interests: None declared.

This article has been peer reviewed.

Correspondence to: Kun-Ta Chou, ale1371@yahoo.com.tw, hbjoue@vghtpe.gov.tw

CMAJ 2014. DOI:10.1503 /cmaj.131547

\section{Methods}

\section{Database}

In Taiwan, the government launched its National Health Insurance Program on Mar. 1, 1995. Of Taiwan's 22.96 million population, 22.60 million were enrolled in this program in 2007. Immigrants are also eligible for this program. The database of this program contains registration files and original claims data for reimbursement. The National Health Research Institutes (NHRI) in Miaoli, Taiwan, is responsible for the National Health Insurance Program and maintains the insurance claims database, the National Health Insurance Research Database (NHIRD; http://nhird.nhri.org.tw/en /index.htm). The database consists of detailed health care data for more than $99 \%$ of Taiwan's population. ${ }^{12}$ The data used in this study were retrieved from the Longitudinal Health Insurance Database 2000, which includes data on a random sample of about 1 million people who were living in 2000. The database includes all of the registration files and medical claims for this group from 1995 to 2010. The released database has been 
validated by the NHRI (http://nhird.nhri.org.tw /date_01.html) as representative of the Taiwanese population and is also one of the largest population-based databases in the world. The NHIRD's accuracy has been validated,,$^{13,14}$ and it appears to be a valid resource for population research in Taiwan. In the Longitudinal Health Insurance Database 2000, each patient's personal identifiable information has been encrypted by the NHRI in a consistent code, which allows linkage of individuals' claims within the database.

\section{Study sample and control}

In this retrospective cohort study, we enrolled a study cohort of adult patients (aged $\geq 20 \mathrm{yr}$ )

Table 1: Characteristics of patients with sleep apnea and matched controls

\begin{tabular}{|c|c|c|c|}
\hline \multirow[b]{2}{*}{ Characteristic } & \multicolumn{2}{|c|}{ No. $(\%)$ of patients* } & \multirow[b]{2}{*}{$p$ value } \\
\hline & $\begin{array}{c}\text { Sleep apnea } \\
n=6816\end{array}$ & $\begin{array}{c}\text { Control } \\
n=27284\end{array}$ & \\
\hline \multicolumn{4}{|l|}{ Age, yr } \\
\hline Mean \pm SD & $46.49 \pm 14.52$ & $46.50 \pm 14.52$ & \\
\hline$<65$ & $5989 \quad$ (87.9) & 23970 (87.9) & $>0.9$ \\
\hline$\geq 65$ & $827 \quad(12.1)$ & 3314 (12.1) & \\
\hline $\begin{array}{l}\text { Follow-up years, } \\
\text { median (IQR) }\end{array}$ & $4.00(2.26-6.30)$ & $4.04(2.29-6.37)$ & 0.4 \\
\hline \multicolumn{4}{|l|}{ Sex } \\
\hline Female & $2542 \quad(37.3)$ & $10175 \quad(37.3)$ & $>0.9$ \\
\hline Male & $4274 \quad(62.7)$ & 17109 (62.7) & \\
\hline \multicolumn{4}{|l|}{ Comorbidity } \\
\hline Diabetes mellitus & $1315 \quad$ (19.3) & $5232 \quad(19.2)$ & 0.8 \\
\hline $\begin{array}{l}\text { Coronary heart } \\
\text { disease }\end{array}$ & $1603 \quad(23.5)$ & 6375 (23.4) & 0.8 \\
\hline Heart failure & (6.6) & $1755 \quad(6.4)$ & 0.6 \\
\hline $\begin{array}{l}\text { Cerebrovascular } \\
\text { disease }\end{array}$ & $869 \quad(12.7)$ & 3437 (12.6) & 0.7 \\
\hline Dementia & $(1.2)$ & $(0.8)$ & 0.01 \\
\hline Epilepsy & (2.4) & $(2.2)$ & 0.2 \\
\hline Parkinson disease & $(1.5)$ & $305 \quad(1.1)$ & 0.02 \\
\hline CKD/ESRD & $760 \quad(11.2)$ & $2996 \quad(11.0)$ & 0.7 \\
\hline Liver cirrhosis & $(2.5)$ & $589 \quad(2.2)$ & 0.1 \\
\hline GERD & (8.1) & 2129 & 0.3 \\
\hline Cancer & (2.7) & (2.4) & 0.2 \\
\hline Asthma & $1012 \quad(14.8)$ & 3996 (14.6) & 0.7 \\
\hline COPD & $1592 \quad(23.4)$ & $6331 \quad(23.2)$ & 0.8 \\
\hline Tuberculosis & (2.5) & (2.3) & 0.2 \\
\hline \multicolumn{4}{|l|}{ Treatment } \\
\hline Statins & (9.1) & 1860 & $<0.001$ \\
\hline Inhaled steroid & (1.2) & $(0.9)$ & 0.02 \\
\hline \multicolumn{4}{|c|}{$\begin{array}{l}\text { Note: } \mathrm{CKD}=\text { chronic kidney disease, } \mathrm{COPD}=\text { chronic obstructive pulmonary disease, } \\
\mathrm{ESRD}=\text { end-stage renal disease, } \mathrm{GERD}=\text { gastroesophageal reflux disease, } \mathrm{IQR}=\text { interquartile } \\
\text { range, } \mathrm{SD}=\text { standard deviation. } \\
\text { *Unless stated otherwise. }\end{array}$} \\
\hline
\end{tabular}

who, between Jan. 1, 2000, and Dec. 31, 2010, were newly diagnosed with sleep apnea (International Classification of Diseases, 9th Revision [Clinical Modification] [ICD-9-CM] codes 780.51, 780.53, 780.57). ${ }^{15}$ The date of enrolment was defined as the date on which sleep apnea was initially diagnosed. A control group of patients without sleep apnea, matched for age, sex and comorbidities, was randomly selected from the same data sets. In both groups, patients were excluded before enrolment if they had a past medical history of pulmonary infection, including pneumonia (ICD-9-CM codes 480.xx486.xx), lung abscess (ICD-9-CM codes 513.xx) or empyema (ICD-9-CM codes 510.xx), to avoid interference from the antecedent infection. Both inpatients and outpatients with sleep apnea were included in our analyses.

The Institutional Review Board of the Taipei Veterans General Hospital approved this study.

\section{Variables}

Comorbidities associated with the development of pneumonia were assessed and matched between the study and control groups, including preexisting diabetes mellitus, hypertension, coronary heart disease, heart failure, cerebrovascular disease, dementia, epilepsy, Parkinson disease, chronic kidney disease, liver cirrhosis, gastroesophageal reflux disease, cancer, asthma, chronic obstructive pulmonary disease and tuberculosis. ${ }^{16}$

\section{Matching}

Patients without sleep apnea were selected for the control group at a ratio of 4 controls per sleep apnea patient by means of incidence density sampling. ${ }^{17,18}$ The control group was matched for each patient's age, sex, comorbidities and year of enrolment. ${ }^{19}$ Matching for age and year of enrolment was within a tolerance range $( \pm 1 \mathrm{yr})$. For the control group, the start of follow-up was defined as the date of the first clinical visit to a medical facility in the enrolment year.

\section{Main outcome measures}

We defined the outcome of the study as occurrence of pneumonia. The diagnosis of pneumonia was based on the presence of compatible symptoms (e.g., cough, fever, sputum production and pleuritic chest pain) and chest radiography. In this study, 2 radiologists (H.-K.W. and L.-A.W) were responsible for validation of pneumonia, as described in the next section. Risk of pneumonia was stratified according to the need for continuous positive airway pressure (CPAP) treatment, which was used as a surrogate marker for severity of sleep apnea. ${ }^{15,20}$ All patients were followed 
from the date of enrolment until the first diagnosis of pneumonia; the date of death; withdrawal from the National Health Insurance Program; or Dec. 31,2010 , if they were free of pneumonia.

\section{Validation}

The identification of patients with pneumonia by ICD-9-CM coding was validated by analysis of randomly selected samples (300 inpatients and 300 outpatients) from the claims database of the Taipei Veterans General Hospital (a 2800-bed tertiary referral hospital in Taiwan) between 2010 and 2012. The contents of this database were used for reimbursements and were similar to those of the National Health Insurance Program's inpatient claims files. Two investigators (H.-K.W. and L.-A.W) independently reviewed the clinical information and imaging records of the selected samples. Cases of disagreement were resolved by discussion. We used the consensus guidelines to identify pneumonia. ${ }^{21}$ To assess interobserver agreement on the identification of pneumonia, we calculated the Cohen $\kappa$ coefficient, which expresses the probability beyond chance $(\kappa=0.00-0.40$ : slight to fair agreement; $\kappa=0.40-0.60$ : moderate agreement; $\kappa=0.60-0.80$ : good agreement; $\kappa=0.80-1.00$ : excellent agreement).

We previously validated the diagnosis of sleep apnea, and part of the results were mentioned in our previous work..$^{20}$ From Jan. 1, 2000, to June 30, 2009, 3766 patients with a diagnosis of sleep apnea at our hospital (ICD-9 codes 780.51, $780.53,780.57)$ were evaluated. Of these, 3124 (83\%) had data from overnight polysomnography (results from self-pay polysomnography or based on unattended portable devices were not included). A total of 2723 patients (87\% of those with polysomnographic data) were given a confirmed diagnosis of obstructive sleep apnea, and 29 patients $(0.9 \%)$ were given a diagnosis of pure central apnea. If the repeated (follow-up) polysomnographic data of the same patients were included, 3363 of the tests confirmed sleep apnea, of which 3333 were obstructive sleep apnea and 30 were pure central apnea.

\section{Statistical analysis}

Extraction, matching and computation of data were performed using the Perl programming language (version 5.12.2). We used a 2005 Microsoft SQL Server for data linkage, processing and sampling. We performed random sampling of claims data for validation using Microsoft Office Excel 2010. We used SPSS software (version 18.0, SPSS, Inc.) to perform the statistical analysis. We used the independent Student $t$ test for continuous variables or the
Pearson $\chi^{2}$ test for categorical variables, as appropriate, to compare the study and control groups. We used the Kaplan-Meier method to conduct the survival analysis, with significance based on the log-rank test. A Cox proportional hazard model was used for multivariate adjustment. We performed multivariate analysis on variables found to be significant between patients with and without pneumonia. We inferred statistical significance at a 2 -sided $p$ value of $<0.05$.

\section{Results}

We identified 8800 patients with sleep apnea from Jan. 1, 2000, to Dec. 31, 2010. After exclusion of patients younger than 20 years $(n=614)$ and those with antecedent pulmonary infection (pneumonia/lung abscess/empyema) $(n=1370), 6816$ patients with sleep apnea (mean age 46.49 $\pm 14.52 \mathrm{yr}$ ) were included. Another 27284 controls without sleep apnea (mean age $46.50 \pm 14.52$ yr) were selected for comparison. The 2 cohorts had similar characteristics (Table 1), except that the sleep apnea group had a higher prevalence of dementia $(1.2 \%$ v. $0.8 \%, p=0.01)$, Parkinson disease $(1.5 \%$ v. $1.1 \%, p=0.02)$ and use of inhaled steroids and statins than the control group. Most enrollees in both groups $(94.7 \%$ of the sleep apnea group and $94.2 \%$ of the control group) were followed until the end of the study (Appendix 1, available at www.cmaj.ca/lookup/suppl/doi:10 .1503/cmaj.131547/-/DC1).

During $4.50( \pm 2.63)$ years of the follow-up period, there were more pneumonia events in the

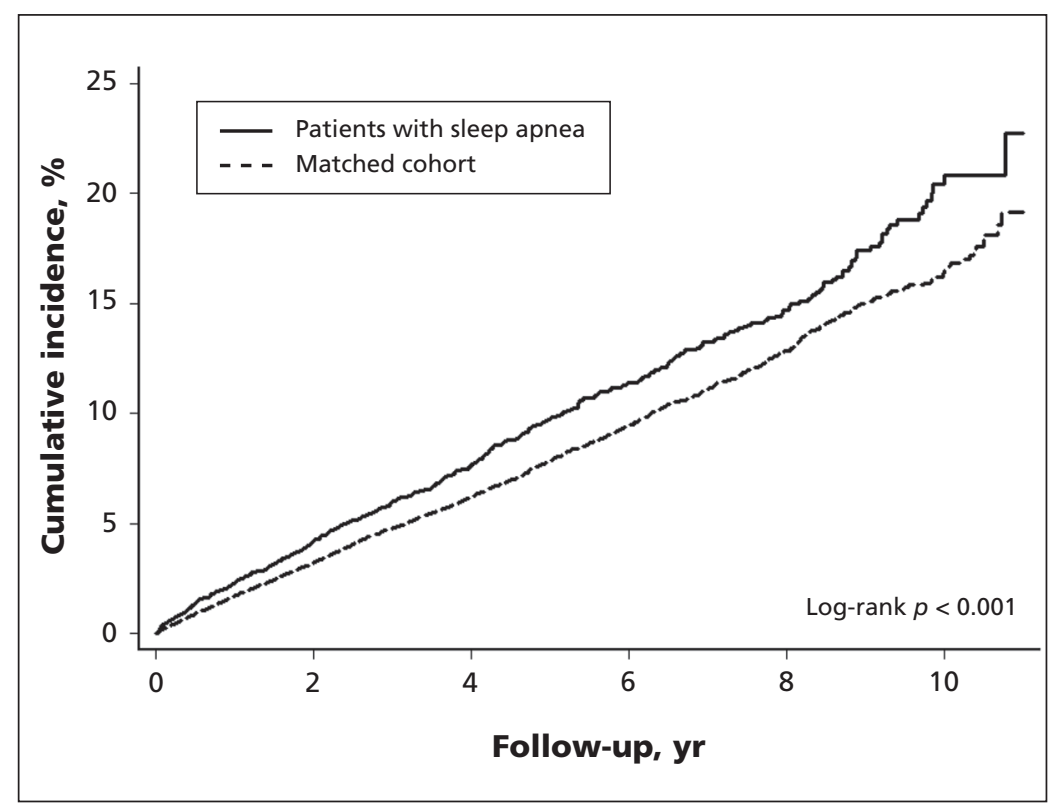

Figure 1: Kaplan-Meier curves showing a significant difference in cumulative incidences of pneumonia among patients with sleep apnea and controls. 
sleep apnea cohort than in the control group (638 [9.36\%] v. 2119 [7.77\%]). Patients with sleep apnea had a significantly higher hazard for incident pneumonia than the control group (log-rank test, $p<0.001$ ) (Figure 1). Incidences in the sleep apnea and control groups were 20.90 and 17.22 persons per 1000 person-years, respectively. Comparing patients with and without pneumonia, those with incident pneumonia were older and had a higher percentage of sleep apnea, diabetes mellitus, coronary heart disease and other comorbidities (Table 2).

After multivariate adjustment, sleep apnea (adjusted hazard ratio [HR] 1.19, 95\% confidence interval [CI] 1.08-1.30) was independently associated with incident pneumonia (Table 3). Other independent factors are shown in Appendix 2,

Table 2: Characteristics of patients with and without pneumonia

\begin{tabular}{|c|c|c|c|}
\hline \multirow[b]{2}{*}{ Characteristic } & \multicolumn{2}{|c|}{ No. (\%) of patients } & \multirow[b]{2}{*}{$p$ value } \\
\hline & $\begin{array}{c}\text { Pneumonia } \\
n=2757\end{array}$ & $\begin{array}{c}\text { No pneumonia } \\
n=31343\end{array}$ & \\
\hline \multicolumn{4}{|l|}{ Age, yr } \\
\hline Mean \pm SD & $55.39 \pm 16.86$ & $45.72 \pm 14.03$ & \\
\hline$<65$ & $1834(66.5)$ & $28125 \quad(89.7)$ & $<0.001$ \\
\hline$\geq 65$ & $923 \quad(33.5)$ & $3218 \quad(10.3)$ & \\
\hline \multicolumn{4}{|l|}{ Sex } \\
\hline Female & 1063 (38.6) & $11654 \quad(37.2)$ & 0.2 \\
\hline Male & 1694 (61.4) & $19689 \quad(62.8)$ & \\
\hline \multicolumn{4}{|l|}{ Comorbidity } \\
\hline Sleep apnea & $638 \quad(23.1)$ & $6178 \quad(19.7)$ & $<0.001$ \\
\hline Diabetes mellitus & $860 \quad(31.2)$ & $5687 \quad(18.1)$ & $<0.001$ \\
\hline $\begin{array}{l}\text { Coronary heart } \\
\text { disease }\end{array}$ & 1036 (37.6) & $6942 \quad(22.1)$ & $<0.001$ \\
\hline Heart failure & $401 \quad(14.5)$ & 1804 & $<0.001$ \\
\hline $\begin{array}{l}\text { Cerebrovascular } \\
\text { disease }\end{array}$ & $690 \quad(25.0)$ & $3616 \quad(11.5)$ & $<0.001$ \\
\hline Dementia & $72 \quad(2.6)$ & $(0.8)$ & $<0.001$ \\
\hline Epilepsy & $98 \quad(3.6)$ & $(2.1)$ & $<0.001$ \\
\hline Parkinson disease & $82 \quad(3.0)$ & $(1.0)$ & $<0.001$ \\
\hline CKD/ESRD & $485 \quad(17.6)$ & $3271 \quad(10.4)$ & $<0.001$ \\
\hline Liver cirrhosis & $104 \quad(3.8)$ & $(2.1)$ & $<0.001$ \\
\hline GERD & $183 \quad(6.6)$ & 2501 & 0.01 \\
\hline Cancer & $132 \quad(4.8)$ & $(2.2)$ & $<0.001$ \\
\hline Asthma & $670 \quad(24.3)$ & $4338 \quad(13.8)$ & $<0.001$ \\
\hline COPD & 1058 (38.4) & $6865 \quad(21.9)$ & $<0.001$ \\
\hline Tuberculosis & $108 \quad(3.9)$ & $(2.2)$ & $<0.001$ \\
\hline \multicolumn{4}{|l|}{ Treatment } \\
\hline Statins & $209 \quad(7.6)$ & 2269 & $<0.001$ \\
\hline Inhaled steroid & $103 \quad(3.7)$ & $(0.7)$ & $<0.001$ \\
\hline
\end{tabular}

Note: $C K D$ = chronic renal disease, $C O P D=$ chronic obstructive pulmonary disease, ESRD = end-stage renal disease, GERD = gastroesophageal reflux disease, $S D=$ standard deviation available at www.cmaj.ca/lookup/suppl/doi:10 .1503/cmaj.131547/-/DC1. After multivariate adjustment, sleep apnea (HR 1.03, 95\% CI $0.70-1.51$ ) was associated with a nonsignificant increase in pneumonia-related mortality (Appendix 3, available at www.cmaj.ca/lookup/suppl /doi:10.1503/cmaj.131547/-/DC1).

Compared with the control group, the adjusted risks of pneumonia among patients with sleep apnea who needed and did not need CPAP treatment were 1.32 (95\% CI 1.12-1.55) and 1.15 (95\% CI 1.04-1.27), respectively (Table 3). The subgroup analysis is presented in Figures 2 and 3. After adjustment for all comorbidities, patients with sleep apnea remained at significantly increased risk of pneumonia compared with controls.

\section{Validation}

A total of 5139 adult inpatients and 13528 adult outpatients had claims data with a diagnosis of pneumonia between Jan. 1, 2010, and Dec. 31, 2012, from which 300 inpatients and 300 outpatients were randomly selected for validation. Among the 300 inpatients, 284 had a confirmed diagnosis of pneumonia whereas 16 did not. Thus, we obtained a sensitivity of $94.7 \%$ for inpatients. Among the 300 outpatients, 277 had a confirmed diagnosis, and the sensitivity was $92.3 \%$. For all patients, the interobserver agreement was good ( $\kappa=0.76,95 \%$ CI 0.64-0.87).

\section{Interpretation}

This study showed that sleep apnea is an independent risk factor for incident pneumonia. Our results also demonstrated an exposure-response relation in that patients with more severe sleep apnea may have a higher risk of pneumonia than patients with sleep apnea of milder severity.

In a study involving hospital-admitted patients with sleep apnea, Spurr and colleagues ${ }^{8}$ found that pneumonia was one of the most common reasons for admission. Another study by Morimoto and coauthors ${ }^{10}$ showed that, among older inpatients with sleep apnea, mortality from all causes was increased as well as from pneu-

Table 3: Association between severity of sleep apnea and risk of incident pneumonia

\begin{tabular}{|ll|}
\hline Group & HR $(95 \% \mathrm{Cl})$ \\
\hline Control & Reference \\
\hline Sleep apnea & $1.19(1.08-1.30)$ \\
\hline CPAP not indicated & $1.15(1.04-1.27)$ \\
\hline CPAP indicated & $1.32(1.12-1.55)$ \\
\hline $\begin{array}{l}\text { Note: } \mathrm{Cl}=\text { confidence interval, CPAP } \\
\text { airway pressure, } \mathrm{HR}=\text { hazard ratio. }\end{array}$ \\
\hline
\end{tabular}


monia. A nested case-control study showed that, among children with sleep apnea, those with pneumonia had a higher rate of obstructive sleep apnea $(79 / 1546,5 \%)$ than those without pneumonia $(6 / 441,1.3 \%)(p<0.001) .{ }^{9}$ In contrast to several studies that showed an association between sleep apnea and pneumonia, Sanner and associates ${ }^{11}$ found that patients with sleep apnea who received CPAP therapy $(n=206)$ had an increased risk of upper airway infections compared with patients who received conservative treatment $(n=40)$, whereas the risk of pneumonia was not significantly increased (only 1 pneumonia event on 3 years' follow-up v. 0 in controls).

The higher risk of incident pneumonia among patients with sleep apnea could be attributed to increased aspiration risk and impaired immunity. Following episodes of apnea-hypopnea, resultant hypoxemia may stimulate patients to breath against a closed airway, therefore causing the intrathoracic pressure to become more negative. ${ }^{22-25}$ The more-negative intrathoracic pressure induces a higher pressure gradient and a vacuum pressure through the upper airway. ${ }^{26}$ Additionally, patients with obstructive sleep apnea are likely to have impaired sensation of the upper airway and to exhibit an impaired swallowing reflex..$^{27,28}$ Both factors may facilitate aspiration of pathogen-containing pharyngeal secretions, saliva or oral contents into the lower respiratory tract. Furthermore, sleep apnea interrupts sleep owing to frequent apnea-related arousals (i.e., sleep fragmentation), which likely adversely affects patients' immunity and renders them susceptible to pneumonia. ${ }^{29}$ In addition, sleep apnea may involve hypercapnia, which has been linked to impaired lung neutrophil function, which could render these patients susceptible to pneumonia. ${ }^{30}$

The use of CPAP may reduce sputum expectoration and increase the chance of pulmonary aspiration. ${ }^{31}$ Addition of a humidifier also provides a potential source of bacterial contamination, inducing the emergence of pneumonia. ${ }^{13,31}$ Based on our results, we suggest that primary care physicians consider sleep disorders among patients with pneumonia who have no other identified risk factors or with recurrent pneumonia. For sleep specialists, our findings may broaden the spectrum of sleep apnea-related complications, which may not be limited to the cardiovascular or neurocognitive aspects. As well, for patients receiving CPAP therapy, every effort should be made to minimize the risk of pneumonia, such as enhanced cleaning of CPAP tubing and humidifier, and vigilance if recurrent pneumonia is noted among CPAP users.

\section{Strengths and limitations}

One particular strength of this study is its nationwide, population-based study design, which could trace nearly all cases of sleep apnea and pneumonia in Taiwan with minimized referral bias, because all respiratory and infectious practice is covered in our insurance system. Additionally, the study's large sample was powered to detect real, even subtle, differences between the 2 cohorts.

Our study also has several limitations. First, diagnoses of sleep apnea and pneumonia that rely on administrative claims data recorded by physicians or hospitals may be less accurate than diagnoses made in a clinical, prospective setting. Patients with underdiagnosed or overdiagnosed sleep apnea resulted in a misclassification bias. However, the nondifferential misclassification bias was a bias toward the null. In ICD-9-CM, pneumonia (480-486.x) was classified by microorganism (bacteria, virus, other.) Imaging of pneumonia was not available in the NHIRD, and we could not take into account all

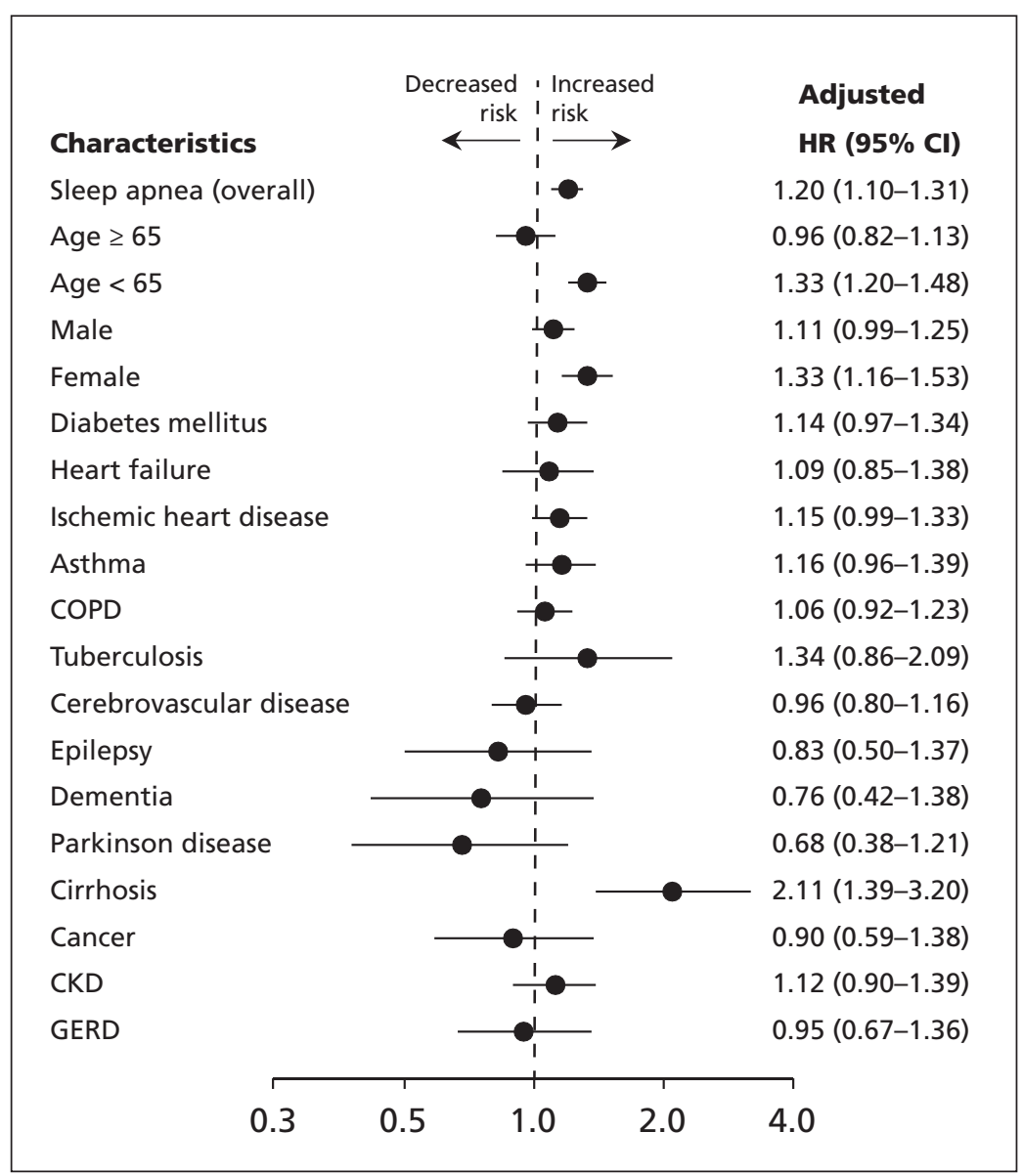

Figure 2: Multivariable analysis showing risk of pneumonia associated with patient characteristics and comorbidities. Values greater than 1.0 indicate an increased risk. $\mathrm{Cl}$ = confidence interval, $\mathrm{CKD}=$ chronic renal disease, $\mathrm{COPD}=$ chronic obstructive pulmonary disease, GERD = gastroesophageal reflux disease, $\mathrm{HR}=$ hazard ratio. 
the types of pneumonia imaging. Nonetheless, we have performed an internal validity of diagnosis of pneumonia by the same ICD-9-CM coding, indicating that the interobserver agreement on the identification of pneumonia was good. Similarly, the diagnosis of sleep apnea has been validated previously. ${ }^{20}$

Second, patient data, including body mass index and smoking history, which may have a substantial impact on propensity to obstructive sleep apnea were not available in the database. Nonetheless, some health consequences related to cigarette smoking would, at least in part, be reflected in the presentation of comorbidities, such as COPD or coronary heart disease, which were covered in our analysis. Alcohol use would

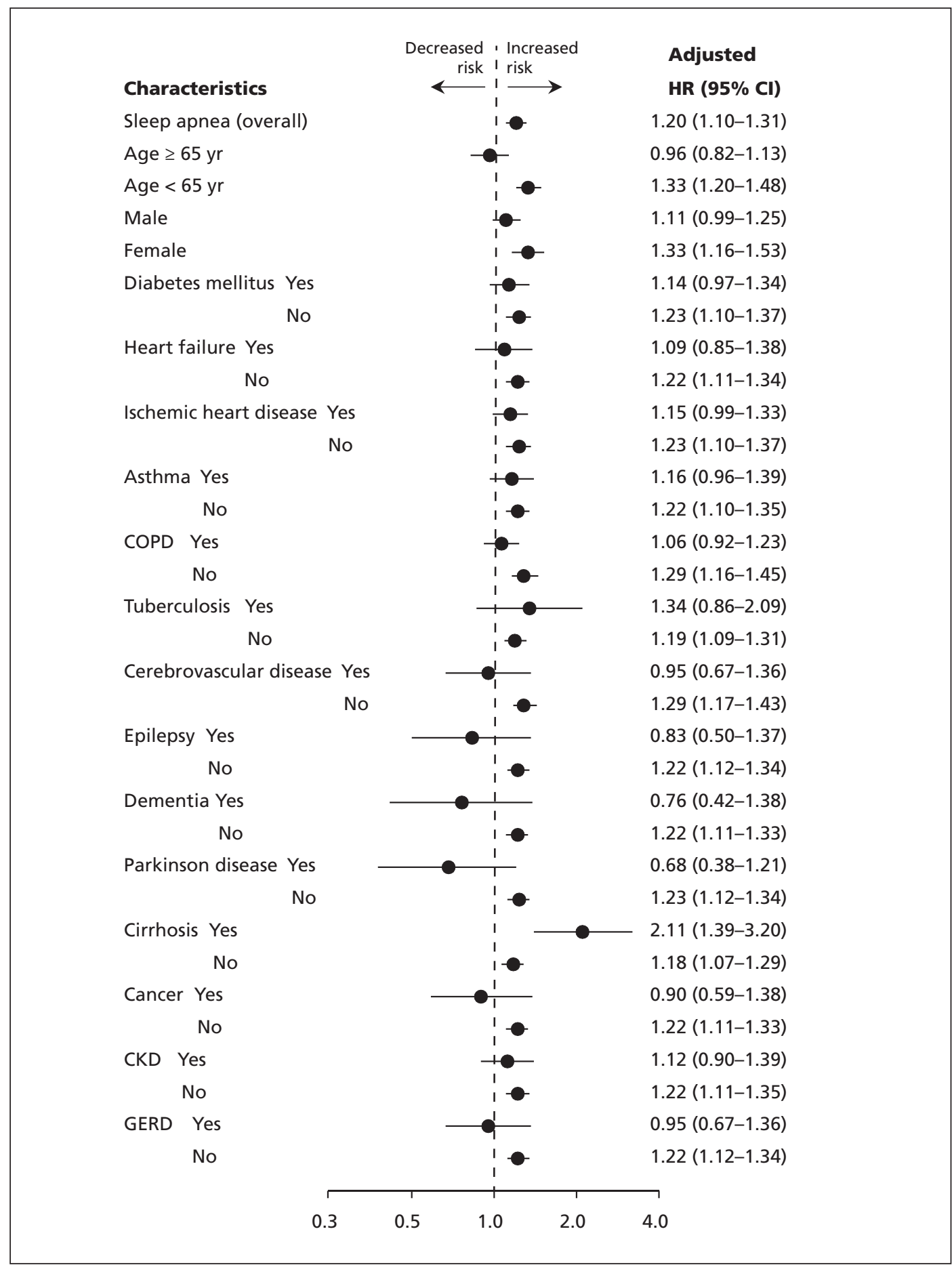

Figure 3: Detailed multivariable analysis showing risk of pneumonia associated with patient characteristics and comorbidities. Values greater than 1.0 indicate an increased risk. $\mathrm{Cl}=$ confidence interval, $\mathrm{CKD}=$ chronic renal disease, COPD = chronic obstructive pulmonary disease, GERD = gastroesophageal reflux disease, $\mathrm{HR}=$ hazard ratio. 
be reflected in the presentation of liver cirrhosis in our analysis.

Third, the need for CPAP was used as a surrogate marker of sleep apnea severity in this study. The choice for CPAP therapy may not solely depend on severity of the disease; other factors, such as comorbidities or patient preference, may influence its use as well.

\section{Conclusion}

Sleep apnea may be a risk factor for pneumonia, and the risk probably increases in accordance with sleep apnea severity.

\section{References}

1. He QY, Feng J, Zhang XL, et al.; Sleep Breath Disorder Group; Society of Respiratory Medicine; Chinese Medical Association. Relationship of daytime blood pressure and severity of obstructive sleep apnea among Chinese: a multi-center investigation in China. Chin Med J (Engl) 2010;123:18-22.

2. Chen R, Xiong KP, Lian YX, et al. Daytime sleepiness and its determining factors in Chinese obstructive sleep apnea patients. Sleep \& Breath 2011:15:129-135.

3. Epstein LJ, Kristo D, Strollo PJ Jr, et al; Adult Obstructive Sleep Apnea Task Force of the American Academy of Sleep Medicine. Clinical guideline for the evaluation, management and long-term care of obstructive sleep apnea in adults. J Clin Sleep Med 2009; 5:263-76.

4. Bucks RS, Olaithe M, Eastwood P. Neurocognitive function in obstructive sleep apnoea: a meta-review. Respirology 2013;18: 61-70.

5. Lattimore JD, Celermajer DS, Wilcox I. Obstructive sleep apnea and cardiovascular disease. J Am Coll Cardiol 2003;41:1429-37.

6. Beal M, Chesson A, Garcia T, et al. A pilot study of quantitative aspiration in patients with symptoms of obstructive sleep apnea: comparison to a historic control group. Laryngoscope 2004;114: 965-8.

7. Besedovsky L, Lange T, Born J. Sleep and immune function. Pflugers Arch 2012;463:121-37.

8. Spurr KF, Graven MA, Gilbert RW. Prevalence of unspecified sleep apnea and the use of continuous positive airway pressure in hospitalized patients, 2004 national hospital discharge survey. Sleep Breath 2008;12:229-234.

9. Goldbart AD, Tal A, Givon-Lavi N, et al. Sleep-disordered breathing is a risk factor for community-acquired alveolar pneumonia in early childhood. Chest 2012;141:1210-5.

10. Morimoto S, Takahashi T, Okaishi K, et al. Sleep apnoea syndrome as a risk for mortality in elderly inpatients. J Int Med Res 2012;40:601-11.

11. Sanner BM, Fluerenbrock N, Kleiber-Imbeck A, et al. Effect of continuous positive airway pressure therapy on infectious complications in patients with obstructive sleep apnea syndrome. Respiration 2001;68:483-7.

12. Wu CY, Chen YJ, Ho HJ, et al. Association between nucleoside analogues and risk of hepatitis B virus-related hepatocellular carcinoma recurrence following liver resection. JAMA 2012;308: 1906-14.

13. Lu TH, Lee MC, Chou MC. Accuracy of cause-of-death coding in Taiwan: types of miscoding and effects on mortality statistics. Int J Epidmiol 2000;29:336-343.

14. Cheng CL, Kao YH, Lin SJ, et al. Validation of the National Health Insurance Research Database with ischemic stroke cases in Taiwan. Pharmacoepidemiol Drug Saf 2011;20:236-42.

15. Chou KT, Huang CC, Chen YM, et al. Sleep apnea and risk of deep vein thrombosis: a non-randomized, pair-matched cohort study. Am J Med 2012;125:374-80.

16. Almirall J, Bolibar I, Serra-Prat M, et al.; Community-Acquired Pneumonia in Catalan Countries Study Group. New evidence of risk factors for community-acquired pneumonia: a populationbased study. Eur Respir J 2008;31:1274-84.
17. Wacholder S, McLaughlin JK, Silverman DT, et al. Selection of controls in case-control studies. I. Principles. Am J Epidemiol 1992; 135:1019-28.

18. Beaumont JJ, Steenland K, Minton A, et al. A computer program for incidence density sampling of controls in case-control studies nested within occupational cohort studies. Am J Epidemiol 1989;129:212-9.

19. Su VY, Liu CJ, Lan MY, et al. Allergic rhinitis and risk of erectile dysfunction: a nationwide population-based study. Allergy 2013:68:440-5.

20. Shiao TH, Liu CJ, Luo JC, et al. Sleep apnea and risk of peptic ulcer bleeding: a nationwide population-based study. Am J Med 2013;126:249-255.

21. Mandell LA, Wunderink RG, Anzueto A, et al. Infectious Diseases Society of America/American Thoracic Society consensus guidelines on the management of community-acquired pneumonia in adults. Clin Infect Dis 2007;44(Suppl 2):S27-72.

22. Horner RL, Shea SA, McIvor J, et al. Pharyngeal size and shape during wakefulness and sleep in patients with obstructive sleep apnoea. $O$ J Med 1989;72:719-35.

23. Morrell MJ, Arabi Y, Zahn B, et al. Progressive retropalatal narrowing preceding obstructive apnea. Am J Respir Crit Care Med 1998; 158:1974-81.

24. Schwab RJ, Gupta KB, Gefter WB, et al. Upper airway and soft tissue anatomy in normal subjects and patients with sleep-disordered breathing: significance of the lateral pharyngeal walls. Am J Respir Crit Care Med 1995;152:1673-89.

25. Schwab RJ, Pasirstein M, Pierson R, et al. Identification of upper airway anatomic risk factors for obstructive sleep apnea with volumetric magnetic resonance imaging. Am J Respir Crit Care Med 2003;168:522-30.

26. Dempsey JA, Veasey SC, Morgan BJ, et al. Pathophysiology of sleep apnea. Physiol Rev 2010;90:47-112.

27. Teramoto S, Sudo E, Matsuse T, et al. Impaired swallowing reflex in patients with obstructive sleep apnea syndrome. Chest 1999;116:17-21

28. Kimoff RJ, Sforza E, Champagne V, et al. Upper airway sensation in snoring and obstructive sleep apnea. Am J Respir Crit Care Med 2001;164:250-5.

29. Ruiz FS, Andersen ML, Martins RC, et al. Immune alterations after selective rapid eye movement or total sleep deprivation in healthy male volunteers. Innate Immun 2012;18:44-54.

30. Gates KL, Howell HA, Nair A, et al. Hypercapnia impairs lung neutrophil function and increases mortality in murine pseudomonas pneumonia. Am J Respir Cell Mol Biol 2013;49:821-8.

31. Gay PC. Complications of noninvasive ventilation in acute care. Respir Care 2009;54:246-57; discussion 257-8.

Affiliations: Department of Chest Medicine (Su VY, Chang, Su W, Perng, Chen Y, Chou), Division of Hematology and Oncology, Department of Medicine (Liu), Sleep Center (Chou), Department of Radiology (Wang), Department of Family Medicine (Chen T), Taipei Veterans General Hospital, Taipei, Taiwan; Department of Radiology (Wu), HepingFuyou Branch, Taipei City Hospital, Taipei, Taiwan; Institute of Public Health (Liu), Institute of Clinical Medicine (Chou), Institute of Emergency, Critical Care Medicine (Chang), School of Medicine (Su VY, Liu, Wang, Chang, Su W, Perng, Chen Y, Chen T, Chou), National Yang-Ming University, Taipei, Taiwan; College of Medicine (Lin), Chang Gung University, Taoyuan, Taiwan

Contributors: Kun-Ta Chou had full access to all the data in the study, and takes responsibility for the integrity of the data and the accuracy of the data analysis. Vincent Yi-Fong Su, Chia-Jen Liu and Kun-Ta Chou were responsible for the study concept and design. Hsin-Kai Wang and Li-An Wu were responsible for validation and for reviewing images. Chia-Jen Liu, Kun-Ta Chou and Yuh-Min Chen analyzed and interpreted the data. All of the authors contributed to supervising the conduct of the study and data collection, and to drafting or revising the manuscript. All of the authors approved the final version. 